\title{
Surface roughness optimization in machining of AZ31 magnesium alloy using $A B C$ algorithm
}

\author{
Abhijith $^{1}$, Pai Srinivasa ${ }^{1}$, D'Mello Grynal ${ }^{1}$ and Hebbar Gautama ${ }^{1 *}$ \\ ${ }^{1}$ NMAM Institute of technology, Nitte-574110, Karnataka, India
}

\begin{abstract}
Magnesium alloys serve as excellent substitutes for materials traditionally used for engine block heads in automobiles and gear housings in aircraft industries. AZ31 is a magnesium alloy finds its applications in orthopedic implants and cardiovascular stents. Surface roughness is an important parameter in the present manufacturing sector. In this work optimization techniques namely firefly algorithm (FA), particle swarm optimization (PSO) and artificial bee colony algorithm (ABC) which are based on swarm intelligence techniques, have been implemented to optimize the machining parameters namely cutting speed, feed rate and depth of cut in order to achieve minimum surface roughness. The parameter $\mathrm{Ra}$ has been considered for evaluating the surface roughness. Comparing the performance of $\mathrm{ABC}$ algorithm with FA and PSO algorithm, which is a widely used optimization algorithm in machining studies, the results conclude that $\mathrm{ABC}$ produces better optimization when compared to FA and PSO for optimizing surface roughness of AZ 31.
\end{abstract}

Keywords: Surface roughness, optimization, Artificial Bee colony (ABC), Firefly algorithm (FA), Particle swarm optimization (PSO).

\section{Introduction}

The applications of Magnesium alloys are very wide. They are used in electronics, automobile, and aerospace fields for its properties such as low density and high strengthweight ratio. Magnesium alloy, with the density of $1700 \mathrm{~kg} / \mathrm{m}^{3}$ is regarded as one of the lightest among the metallic materials because aluminum alloys are $35 \%$ heavier than $\mathrm{Mg}$ alloys [3]. AZ31 is a magnesium alloy which consists of $96 \%$ magnesium, $3 \%$ aluminium and $1 \%$ zinc [5]. Dry milling is widely used in industrial manufacturing as a high performance cutting technology. Milling operation is required to produce finished products [6]. Surface integrity in machined products is emerging as the new focus in machining research [6]. Guo et al. (2010) analysed the surface integrity by high speed dry milling of $\mathrm{Mg}$ alloy. The findings of this study are high-speed dry milling can be performed using PCD inserts safely with slight flank build-up and surface integrity characterized by low roughness [2]. Kaining Shi et al. 2015) conducted dry face milling on magnesium alloy.

\footnotetext{
*Corresponding author: gouthamahebbar@nitte.edu.in
} 
Taguchi with grey relational analysis of experimental data was carried out to determine an optimum combination of machining parameters for better surface roughness. Feed rate was regarded as the most dominant factor influencing surface integrity which was found out by the analysis of variance of grey relational grade. The optimum combination of process parameters were validated by validation experiments and the validations revealed that the Taguchi with grey relational analysis is an efficient method to determine available cutting parameters for a desired surface integrity during milling of magnesium alloy. [6]. Grigoraş et al. (2015) analysed the influence of milling parameters on surface roughness of AZ61A, a magnesium-aluminium alloy. The results of ANOVA analysis revealed that only speed and feed have a significant impact [7]. Zagórski et al conducted end milling experiments on AZ31 and AZ91 alloy and they concluded that the best surface quality was achieved for a tool with a PCD cutting edge and the worst for a coated solid carbide tool and slightly higher roughness parameters were obtained for AZ31 than for AZ91 [8]. Yusup et al. (2012) presented an overview and comparison of the research work carried out during 2007-2011, that used evolutionary optimization techniques to optimize machining process parameters. Five techniques namely genetic algorithm, simulated annealing, particle swarm optimization, ant colony optimization and artificial bee colony (ABC) were considered. And among the various machining parameters that were optimized, surface roughness was the main parameter, followed by machining costs and material removal rate [9]. There have been some efforts with regard to use of optimization techniques in machining magnesium alloys to improve surface integrity / surface roughness. There have been very less reported literature regarding study of optimization techniques like Genetic Algorithm and the newer evolutionary optimization techniques for the optimization of surface roughness in machining of magnesium alloys. In this study the focus is on the use of evolutionary optimization techniques like PSO, Firefly algorithm (FA) and ABC for optimizing surface roughness in terms of parameter $\mathrm{R}_{\mathrm{a}}$ during milling of magnesium alloy AZ31. The cutting speed, feed rate and depth of cut are to be optimized.

\section{Experimentation}

The work piece used in this study is AZ31 magnesium alloy of width $60 \mathrm{~mm}$ and length $110 \mathrm{~mm}$. CNC vertical machining center (BMW 45 T 20 BFW make) which is having 6000 $\mathrm{rpm}$ as the maximum spindle speed was utilized for conducting experiments. Face milling experiments were carried out for a length of $110 \mathrm{~mm}$. Milling experiments were conducted with cutter diameter of $50 \mathrm{~mm}$ and single uncoated carbide insert for different cutting conditions using three level full factorial design. The specification of the milling cutter is R217.69-2020.3-12-2AN (SECO make) and insert specification is XOEX120404FR-E06, H15 (SECO make) with corner radius of $0.8 \mathrm{~mm}$. After each machining pass, the tool insert is removed from the tool holder and inspected for wear using Mitutoyo make Tool makers' microscope (TM505/510). No tool wear was observed for all the experiments carried out. Dry machining was carried out with no use of coolant. 
Table 1. Machining parameters

\begin{tabular}{|l|l|l|}
\hline $\begin{array}{l}\text { Cutting speed } \\
(\mathrm{m} / \mathrm{min})\end{array}$ & $\begin{array}{l}\text { Feed rate } \\
(\mathrm{mm} / \text { tooth })\end{array}$ & $\begin{array}{l}\text { Depth of cut } \\
(\mathrm{mm})\end{array}$ \\
\hline 200 & 0.4 & 0.15 \\
\hline 350 & 0.8 & 0.25 \\
\hline 500 & 1.2 & 0.35 \\
\hline
\end{tabular}

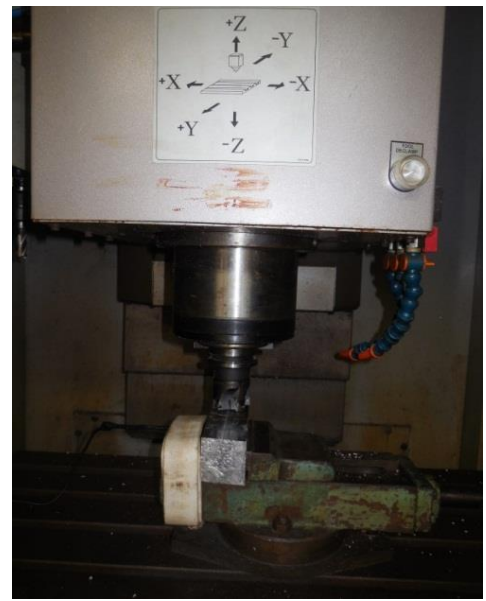

Fig. 1. Machining setup

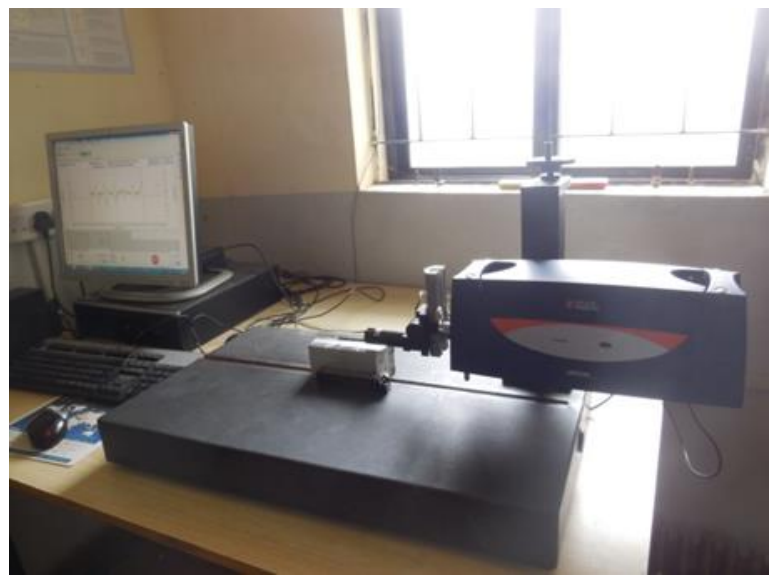

Fig. 2. Surface roughness measurement

Surface roughness has been measured after each machining pass using Taylor Hobson Taly Surf 50 which is a contact type stylus instrument. The traverse length of stylus is set for 2.5 $\mathrm{mm}$ which is considered while measuring the surface roughness parameter $R_{a}$ (arithmetic average surface roughness). The surface roughness parameter $R_{a}$ is measured at three different locations along the mid portion of the milled surface and mean value has been calculated. Fig. 1 shows the machining setup and Fig. 2 shows the surface roughness measurement process.

\section{Optimization techniques}

Determining the optimum machining conditions are of great concern in manufacturing environments, where economy of machining operation plays an important role to survive in the market. In highly competitive manufacturing industries nowadays, the final goal of a manufacturer is to produce high quality products. Surface roughness is one of the output parameter which influences the quality of the machined products. Surface roughness depends upon process parameters. In optimizing the machining process parameters, the selection of these parameters are important. It can be done based on human judgment and experience, but this will not always result in optimal results. Machining process is very complex and there are several factors, which influence their performance [9]. Optimization techniques are useful to find the optimum solution. An optimization algorithm is an iterative procedure executed by comparing different solutions till a satisfactory solution is obtained. The method selected for a particular case is dependent on the objective function, 
the nature of constraints, number of independent and dependent variables [10]. Currently a number of optimization techniques are being used to optimize machining process parameters and include evolutionary or metaheuristic techniques, most of which are inspired by the nature of animal behavior and include genetic algorithm (GA), PSO, ABC, ACO etc [9]. In this research work, three optimization techniques namely PSO, FA and $\mathrm{ABC}$ algorithm have been applied for optimizing surface roughness during milling magnesium based alloys.

\subsection{Artificial Bee Colony algorithm}

The algorithm consists of colony of artificial bees contain bees of three categories: employed bees, onlookers and scouts. Initial half of the bee colony consists of the artificial bees and the latter half includes the onlookers. One employed bee is utilized for each food source. The employed bee without a food source becomes a scout. The food search carried out by the artificial bees is as follows:

- Food source is identified by employed bees within the neighbourhood of the food source in their memory.

- Onlookers gain information about food sources and select one food source from employed bees inside the hive.

- A food source is selected by onlooker within the boundary of food sources chosen by themselves.

- A scout is an employed bee without a source will search for a new food source randomly.

The four main steps are:

Initialize

REPEAT

(1) Employed bees are moved onto their food sources and determine their nectar amounts.

(2) Circulate the onlookers onto the various food sources and determine their nectar amounts.

(3) Scouts are being moved to search for fresh food sources.

(4) Memorize the best possible food source detected so far.

The steps are repeated until requirements are met. [15]

\subsection{Objective function development}

For any non-conventional optimization problem, it is very much essential to define the objective function. There are several methods to obtain the objective function when studying a predictive task. Artificial Neural Network (ANN) based objective functions have been used in all the optimization techniques studied in this work. Puneet N. P. et al. (2015) in a study related to surface roughness optimization in high speed turning of mild steel have established that ANN based objective function is better than Response Surface Methodology (RSM) based objective function in the use of both genetic algorithm (GA) and PSO techniques [10].

The primary objective of this work is to optimize (minimize) surface roughness parameter $\mathrm{R}_{\mathrm{a}}$. The objective function is of the form,

$$
R_{a}=\left[V_{c} f d V_{c}^{2} f^{2} d^{2} V_{c} * f V_{c} * d f * d\right][C]
$$

$[\mathrm{C}]=$ matrix containing coefficients of terms in the equation 


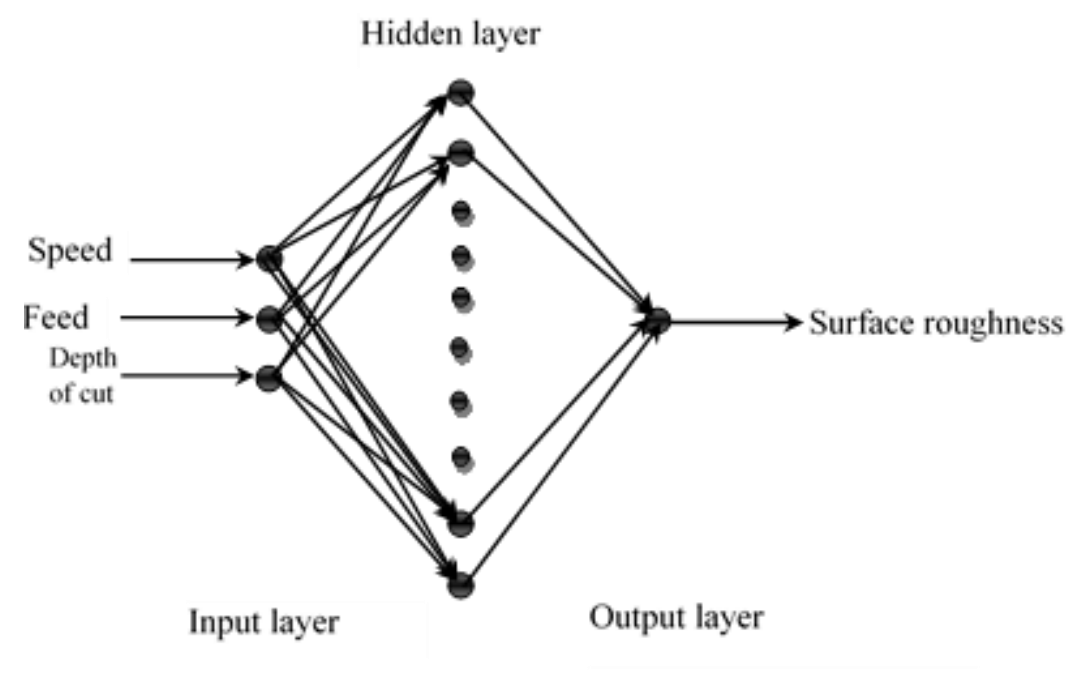

Fig. 3. ANN Model for $\mathrm{R}_{\mathrm{a}}$

A Multi-Layer Perceptron (MLP) model has been developed using the neural network toolbox in MATLAB [13]. The network has been trained using tansig and logsig transfer along with different training algorithms namely trainlm, trainbfg, trainscg and traincgf. The neurons in the hidden layer has been changed from 5 to 25 and the model which gave the highest $\mathrm{R}^{2}$ (correlation coefficient) has been selected. The highest $\mathrm{R}^{2}$ of 0.998 is achieved using tansig transfer function with trainlm (Levenberg-Marquardt) training algorithm for 13 hidden neurons with an error of $5.64 * 10^{-5}$ in 1000 epochs.

\subsection{Implementation of Algorithms}

\subsubsection{Firefly algorithm}

The implementation of FA is based on the MATLAB code developed by Xing-She Yang at MATHWORKS file exchange website [12]. The FA algorithm is run for 100 iterations. The input parameters for FA include population of fireflies which have been varied between 15 and 100 , randomization is varied between 0.3 and 0.8 , light absorption coefficient is set a value of unity, the attractiveness coefficient is set to 0.2 .

The range of input parameters are:

Range of milling speed is $200 \mathrm{~m} / \mathrm{min}-500 \mathrm{~m} / \mathrm{min}$

Range of feed rate is $0.4 \mathrm{~mm} /$ revolution $-1.2 \mathrm{~mm} /$ revolution

Range of DOC is $0.15 \mathrm{~mm}-0.35 \mathrm{~mm}$

\subsubsection{PSO algorithm}

The implementation of PSO algorithm has been done in MATLAB based on the work done by S.B.Raja and N. Bhaskar (2011) [14]. The PSO algorithm is run for 100 iterations. The particle dimension is set to 5, with population size varied between 20 and 40 . The learning factors are given the values 1 and 3. The range of input parameters are same as described in previous section. 


\subsubsection{ABC algorithm}

The population size is varied between 15 and 25.The setting of different parameters are as follows: Number of iterations $=40$, Dimensions of particle $=3$. The range of input parameters are same as described previously.

\section{Results and discussion}

The goal of this work is to minimize surface roughness in terms of parameter $\left(R_{a}\right)$. The values of the simulation parameters for all the algorithms have been set by trial and error. The minimum value of the surface roughness parameters obtained using all the algorithms is given in Table 3 along with the experimental values.

Table 2. Performance of Optimization algorithms

\begin{tabular}{|l|l|l|l|l|l|}
\hline $\begin{array}{l}\text { Roughness } \\
\text { parameter }\end{array}$ & Algorithm & $\mathrm{V}_{\mathrm{c}}$ & $\mathrm{f}$ & $\mathrm{DOC}$ & $\begin{array}{l}\mathrm{R}_{\mathrm{a}} \\
\mu \mathrm{m}\end{array}$ \\
\hline $\mathrm{R}_{\mathrm{a}}$ & PSO & 499.871 & 0.4 & 0.347 & 0.4606 \\
\hline & FA & 500 & 0.471 & 0.265 & 0.374 \\
\hline & ABC & 462.5 & 0.45 & 0.27 & 0.36 \\
\hline & $\begin{array}{l}\text { Experimental } \\
\text { values }\end{array}$ & 500 & 0.4 & 0.35 & 0.4146 \\
\hline
\end{tabular}

It is recommended to use high cutting speed, low feed rate and high depth of cut for obtaining minimum $\mathrm{R}_{\mathrm{a}}$.

Table 3. Comparison of optimization algorithms

\begin{tabular}{|c|c|c|c|c|c|}
\hline $\begin{array}{c}\text { Comparable } \\
\text { techniques }\end{array}$ & Parameter & Techniques & $\begin{array}{l}\text { Surface } \\
\text { Roughness } \\
\text { parameter } \\
\mathrm{R}_{\mathrm{a}}\end{array}$ & $\begin{array}{l}\text { Better } \\
\text { technique }\end{array}$ & \% Improvement \\
\hline ABC and FA & $\mathrm{R}_{\mathrm{a}}$ & $\mathrm{ABC}$ & 0.36 & ABC over FA & $3.74 \%$ \\
& & FA & 0.374 & & \\
\hline ABC and PSO & $\mathrm{R}_{\mathrm{a}}$ & $\mathrm{ABC}$ & 0.36 & $\mathrm{ABC}$ over & $22.8 \%$ \\
& & PSO & 0.4606 & PSO & \\
\hline
\end{tabular}

The focus of the present work is to study the use of $A B C$ algorithm for optimization of $\mathrm{R}_{\mathrm{a}}$ of AZ31 magnesium alloy during milling. The desired surface roughness value is in the range of $R_{a}(0.31$ to $0.4 \mu \mathrm{m})$. The focus in optimization studies is to identify the minimum value of $R_{a}$, which can be achieved practically based on the experimental studies carried out for the given machining operation, alloy machined and cutting conditions used. Table 4 gives the comparison in performance between $\mathrm{ABC}$ and other two algorithms. The first comparison is between $\mathrm{ABC}$ and FA. It is found that $\mathrm{ABC}$ is better than $\mathrm{FA}$ in minimization of surface roughness and the improvement is $3.74 \%$. The next comparison is between $\mathrm{ABC}$ and PSO and the improvement is $22.8 \%$. Compared to FA and PSO, ABC is 
better and its performance is much better than PSO when compared to FA. ABC algorithm is very effective in these kinds of applications. There is no much difference in the execution times of all the three algorithms.

\subsection{Validation experimentation}

The results obtained have been validated by conducting an experiment, by setting the optimized cutting conditions obtained from ABC namely cutting speed, feed rate and depth of cut as $500 \mathrm{~m} / \mathrm{min}, 0.4 \mathrm{~mm} /$ tooth and $0.374 \mathrm{~mm}$ respectively. The surface roughness value obtained is $0.34995 \mu \mathrm{m}$ (average value). A comparison with the values obtained using $\mathrm{ABC}$ has resulted in an error of $2.792 \%$. This establishes the effectiveness of ABC for optimization of surface in milling of magnesium alloy.

\section{Conclusions}

In the present work, the main objective is to obtain minimum surface roughness during milling of magnesium alloy AZ31.To achieve this, optimal machining parameters have been obtained using different optimization algorithms like firefly algorithm, ABC algorithm and a widely used algorithm PSO. The focus is to compare ABC algorithm with firefly and PSO. The objective function for all algorithms has been obtained from output of an ANN model. The following important conclusions can be drawn from the study.

1. ABC algorithm is found to be better compared to firefly and PSO in terms of minimization of $\mathrm{R}_{\mathrm{a}}$.

2. From the results it is preferred to use high cutting speed, low feed rate and high depth of cut for obtaining minimum $\mathrm{R}_{\mathrm{a}}$.

3. The validation results has resulted in an error of only $2.792 \%$ for minimization of $\mathrm{R}_{\mathrm{a}}$.

\section{References}

1. Xue-Nan GU et al., "Magnesium based degradable biomaterials", Front. Mater. Sci., Vol.8, No.3, (2014), pp 200-218.

2. Y.B. Guo and M. Salahshoor, "Process mechanics and surface integrity by high speed dry milling of biodegradable magnesium-calcium implant alloys", CIRP Annals Manufacturing Technology, Vol. 59, (2010), pp 151-154.

3. Kaining Shi, Dinghua Zhang and Junxue Ren, "Optimization of process parameters for surface roughness and microhardness in dry milling of magnesium alloy using Taguchi with grey relational analysis", Int. J. Adv. Manuf. Technol., Vol.81, (2015), pp 645651.

4. Yongjun Chen et al., "Recent advances on the development of magnesium alloys for biodegradable implants" Acta Biomaterialia 10 (2014) 4561-4573.

5. Shaoxiang Zhang et al., "Research on an $\mathrm{Mg}-\mathrm{Zn}$ alloy as a degradable biomaterial", Acta Biomaterialia 6 (2010) 626-640.

6. Kaining Shi et al., "Effect of cutting parameters on machinability characteristics in milling of magnesium alloy with carbide tool", Advances in Mechanical Engineering (2016), Vol. 8(1) pp 1-9.

7. Grigoraş, Cosmin-Constantin, and Gheorghe Brabie. "The influence of milling parameters on the surface roughness in the case of magnesium alloy AZ61A." Elastic 3 , no. 20 (2015) pp 41-45. 
8. Zagórski, Ireneusz, and Józef Kuczmaszewski. "Selected problems of effectiveness of processing of magnesium alloys with a Kordell design toll." Management and Production Engineering Review, Vol. 4, (2011), pp 90-96.

9. Norfadzlan Yusup, Azlan Mohd. Zain and Siti Zaiton Mohd. Hashim, "Evolutionary techniques in optimizing machining parameters: Review and recent applications (20072011)”, Expert System with Applications, Vol.39, (2012), pp 9909-9927.

10. Puneet N.P., Srinivasa Pai P., and Grynal D'mello, “Optimization techniques in Turning - A review”, Manufacturing Technology Today, A CMTI Publication, May 2015, pp 3-21.

11. Grynal D’Mello, Srinivasa Pai P. and Puneet N. P., "Optimization studies in High Speed turning of Ti-6Al-4V", Applied Soft Computing, Vol. 51, (2017), pp 105-115.

12. X.-S. Yang, Firefly Algorithm, Mathworks File Exchange Website, December2010 http://www.mathworks.com/matlabcentral/fileexchange/29693-firefly-algorithm.

13. MATLAB and STATISTICAL Tool box, R 2012A, The Mathworks Inc., Natick, MA, 2013.

14. S.B.Raja and N.Baskar, "Particle swarm optimization technique for determining optimal machining parameters of different workpiece materials in turning operation", Int. J. Adv. Manuf. Technol., Vol.54, No. 5-8, (2011), pp 445-463.

15. D. Karaboga, B. Basturk, "On the performance of artificial bee colony (ABC) algorithm”, Applied Soft Computing, Vol. 8, (2008), pp 687-697 